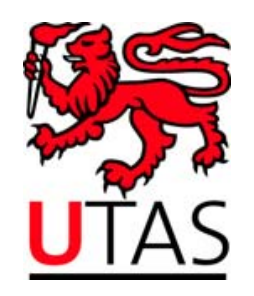

SCHOOL OF ECONOMICS AND FINANCE

Discussion Paper 2012-03

Endogenous Crisis Dating and Contagion Using Smooth Transition Structural GARCH

Mardi Dungey, George Milunovich, Susan Thorp and Minxian Yang 


\title{
Endogenous crisis dating and contagion using smooth transition structural GARCH
}

\author{
Mardi Dungey \\ School of Economics and Finance, University of Tasmania, Australia \\ George Milunovich \\ Department of Economics, Macquarie University, Australia \\ Susan Thorp \\ Finance Group, University of Technology, Sydney, Australia \\ Minxian Yang \\ School of Economics, University of New South Wales, Australia
}

August 29, 2012

Corresponding author: Mardi Dungey; Address: School of Economics and Finance, University of Tasmania, Private Bag 85 Hobart, Tasmania, 7001, Australia; Telephone: +61 36229 5797; Email: mardi.dungey@utas.edu.au 


\begin{abstract}
Detecting contagion during financial crises requires demarcation of crisis periods. This paper presents a method for endogeneous dating of both the start and finish of crises, coupled with the statistical detection of contagion effects. We couple smooth transition functions with structural GARCH to identify both features of markets in crisis, and provide conditions under which these effects will be identified. To illustrate we apply the framework to US financial returns in REITS, S\&P500 and Treasury bonds indices over the period 2001 to 2010, and clearly identify four phases consistent with a pre-crisis period to October 2007, two phases of crisis up to and following late August 2008, and a post-crisis phase dating from June 2009. The evidence strongly supports changes in the transmission mechanisms of shocks between asset returns during the crisis, and particularly contagion from equity markets to REITS. The post-crisis period has not returned to pre-crisis relationships.
\end{abstract}

JEL classification: G01; C51;

Key words: Contagion; Structural GARCH; Global Financial Crisis;

Detecting and measuring contagion effects during financial crises is a challenging empirical problem. One of the most pervasive issues in the literature is the demarcation of crises from the non-crisis periods preceding them, and - even more arduous - detection of the return to normal conditions marking the 'end' of a crisis.1 Fry, Hsaio and Tang (2011) overview the plethora of choices for crisis dates across almost 70 papers.

Crises and contagion effects involve increases in volatility, at both market and individual asset level, changes in transmission mechanisms between assets compared with non-crisis conditions, and are often accompanied by institutional actions to prevent or mitigate the observed or anticipated impacts of these changes. These three crisis features are therefore potential indicators to demarcate a crisis period - but they have substantial drawbacks. For example, changes in transmission mechanisms may also occur simply in response to market developments, such as new products. Additionally, many papers detect contagion via tests for transmission changes, and thus need an independent means

\footnotetext{
${ }^{1}$ See for example the discussion in Jacobs et al. (2005).
} 
of identifying the relevant periods $\mathrm{I}^{2}$ Institutional intervention is likely to be an imperfect indicator in most instances. For example, although the ECB interventions on August 9, 2007 are often used to date the beginning of the global financial crisis, it is clear that this was a response to already heightened anxiety in the markets $3^{3}$ Since changes in transmission and institutional interventions present these problems, we are left with empirical measures, such as heightened volatility, where the primary issue is determining appropriate thresholds for dating crises. 4

This paper develops a method which both endogenously detects a crisis period and measures the contagion effects within the identified crisis. In order to do this we take advantage of structural changes that are evident in both the transmission mechanisms and the volatility of the data over time. We combine smooth transition functions, which enable us to differentiate crisis and non-crisis periods, with the dynamics of structural shocks identified through a structural multivariate GARCH model. Effectively, we combine the advances of smooth transition such as Granger (1993), van Dijk, Teräsvirta, Frances (2002), and Silvennoinen and Teräsvirta (2009) with the GARCH framework of Dungey et. al (2010). The smooth transition models use logistic functions of time to create convex combinations of structural parameters through different phases of non-crisis and crisis, where the matrix of structural linkages between assets is allowed to shift between each phase. An attractive feature of the smooth transition approach is that these shifts can be slow or sudden, depending on the slope of the transition function.

As an illustration of the efficacy of the method we apply it to US financial markets during the period June 17, 2001 to September 16, 2010 for three important asset classes:

\footnotetext{
${ }^{2}$ For example, Forbes and Rigobon (2002) and Dungey and Martin (2007) both impose exogenous dates while Caporale, Cipollini and Spagnolo (2005) select endogenous break points in a form of a sup-Wald test based on largest critical values for the significance of contagion detecting dummies.

${ }^{3}$ Examples of institutional or event based dating is the use of 2 July 1997 - the devaluation of the Thai bhat - to date the beginning of the East Asian crisis and the move by Malaysia to impose capital controls at the end of August 1998 as its endpoint; the announcement of delays in Russian bond repayments and leakage of letters to LTCM clients for the 1998 crises, the collapse of Lehman Brothers to date the second phase of the 2007-2009 crisis, the NBER trough to date the end of this same crisis.

${ }^{4}$ Some examples include Eichengreen, Rose and Wyplosz (1996), Boyson, Stahel, Stulz (2010) and break point tests such applied by Guidolin and Tam (2010) for spreads.
} 
property, equities and fixed interest. Specifically we use the FTSE NAREITS index, the S\&P500 index and the Bank of America Merrill Lynch US Treasury index. The smooth transition component of the framework identifies abrupt transitions from the pre-crisis to crisis period on October 1, 2007 - following the bailout of Northern Rock in the UK, an FOMC action to lower US interest rates and a large depreciation of the US dollar against the Euro. A second phase of the crisis is then identified as occurring from August 20, 2008, less than one month prior to the formal conservatorship of Fannie Mae and Freddie Mac, the bankruptcy of Lehman Brothers and bailout of AIG. Finally, we identify a transition to a further phase from June 18, 2009. This last date coincides with regulatory reform announcements in the US, and the subsequent NBER dating of the business cycle trough in this quarter. The dates selected in our data-driven process are consistent with the event based approach used elsewhere in the literature but by choosing them endogenously we avoid the potential sensitivity of our results to small changes in exogenously chosen dates (see, for example, the sensitivity analysis reported in Dungey et al. (2011)).

In the same dataset we also observe significant changes in the transmission linkages between the different assets during the identified phases. There are dramatic changes in the influence of REITs shocks, which become much less important during the crisis than in the pre-crisis period, and we observe a flight-to-quality phenomenon where the usual linkage between equity and bond index returns becomes insignificant during periods of stress. The evidence supports the existence of contagion from equity market shocks to the REITS during both phases of the crisis. Finally, after June 18, 2009, we do not find that pre-crisis linkages are restored. There remain significant changes in the linkages, and the transmissions from stock markets to REITs remain higher than in the pre-crisis period. In the light of subsequent events with the emergence of the Greek and European sovereign debt crisis from January 2010, it is quite possible that the period from June to September 2010 should be identified as as a further phase of crisis, rather than a true post-crisis period. However, our approach clearly marks out the transition and changes 
in linkages which occur across these four distinct phases in recent history, and although the endogenously determined dates are consistent with an exogenous dating story, they are neither determined by, nor reliant upon, such a construct.

We begin with an outline of the model in section 1 followed by a discussion of identification 2. Section 3 describes the estimation and inference from the application of the model to the financial crisis. In section 4 we conclude and explore possibilities for further work.

\section{The Modelling Framework}

Let a $k$-dimensional vector process $\boldsymbol{Y}_{t}$ with contemporaneous interdependence be described by the system:

$$
B Y_{t}=u_{t}
$$

where the $k \times k$ matrix $\boldsymbol{B}$, with diagonal elements $b_{i i}$ normalized to one, determines the contemporaneous interdependence. Here the conditional mean of $\boldsymbol{Y}_{t}$ (a vector autoregression) is suppressed for the sake of brevity. Its absence does not affect the consideration of regime transitions or parameter identification that follow because the parameters in the conditional mean are all identified as long as $\boldsymbol{B}$ is identified. The entries in the vector $\boldsymbol{u}_{t}$ are uncorrelated structural innovations

$$
\boldsymbol{u}_{t}=\boldsymbol{g}_{t} \boldsymbol{e}_{t}
$$

where $\boldsymbol{g}_{t}$ is a $k \times k$ diagonal matrix and $\boldsymbol{e}_{t}$ is a $k \times 1$ vector of i.i.d. standard normal innovations. In fact $\boldsymbol{g}_{t}$ is the square root of a diagonal GARCH process. This structure has precedents in the crisis and contagion literature in Dungey et al (2010) and Caporale et al (2005). 


\subsection{Transition, Phases and Contagion}

The model in (1) and (2) assumes that contemporaneous linkages, $\boldsymbol{B}$, are constant. However, changes to transmission processes, such as are associated with moves from non-crisis to crisis conditions associated with contagion, may create modifications to $\boldsymbol{B}$. (See, among others, Favero and Giavazzi 2002; Forbes and Rigobon 2002; Dungey and Martin 2007; and Pesaran and Pick 2007.) To accommodate regime changes, we augment the model with smooth transition functions to allow for gradual or rapid switching between regimes. The parameters of the transition functions determine how the regime changes. (See, for example, Granger 1993; van Dijk, Teräsvirta, Frances 2002; and Silvennoinen and Teräsvirta 2009.)

Specifically, we formulate the time varying linkages as:

$$
\boldsymbol{B}_{t} \boldsymbol{Y}_{t}=\boldsymbol{u}_{t}
$$

and we allow $\boldsymbol{B}_{t}$ to be a convex combination of up to $N$ invertible linkage matrices $B_{0}, B_{1}, . ., B_{N}$, where the diagonals are all normalized to one,

$$
\boldsymbol{B}_{\boldsymbol{t}}=\left(1-S_{N}\right)\left[\ldots\left\{\left(1-S_{2}\right)\left[\left(1-S_{1}\right) B_{0}+S_{1} B_{1}\right]+S_{2} B_{2}\right\} \ldots\right]+S_{N} B_{N} .
$$

The linkage matrices are combined by $N$ logistic transition functions

$$
S_{j}=\left(1+e^{-\gamma\left(x_{t}-c_{j}\right)}\right)^{-1}, \quad \gamma>0, \quad j=1, \ldots, N .
$$

where $x_{t}=t / T$ is the time fraction, and $c_{j}$ is the center of the transition between regimes $j-1$ and $j$, where $0<c_{1}<c_{2} \cdots<c_{N}<1$. If the transition speed $\gamma$ is high, the model effectively jumps between regimes. In the first period, for example, while $x_{t}$ remains below the first time threshold $c_{1}$, the values of the transition functions $S_{j}$ for $j>0$ are all close to zero and $\boldsymbol{B}_{t}$ is made up mostly of the linkage matrix $B_{0}$. As $x_{t}$ moves beyond $c_{1}$, the value 
of $S_{1}$ rapidly approaches one, while $S_{2}, \ldots, S_{N}$ are still close to zero, and $\boldsymbol{B}_{t}$ effectively becomes $B_{1}$. As the time index $t$ increases, $x_{t}$ goes through each of $\left(c_{1}, c_{2}, \ldots, c_{N}\right)$ and $\boldsymbol{B}_{t}$ assumes each of $\left(B_{0}, B_{1}, \ldots, B_{N}\right)$ accordingly.

An advantage of the smooth transition model over a regime switching model is that the transition function is continuous and differentiable, and the likelihood is a smooth function of parameters. For a given number of regimes or phases, when standard regularity conditions hold, the maximum likelihood estimators are consistent and asymptotically normal. The asymptotic normality makes inference about $c_{j}$ straightforward.

Contagion is often evidenced by changes in the immediate transmission of shocks between assets during times of stress. In our framework, changes in the contemporaneous linkage matrices, $\left(B_{0}, B_{1}, \ldots, B_{N}\right)$, have a natural interpretation as contagion effects. Increases or decreases in the strengths of the linkages in different regimes can be tested by comparing the size of individual (or all) elements of $B_{1}, \ldots, B_{N}$ with the pre-crisis linkages of $B_{0}$.

\subsection{Structural GARCH}

A structural GARCH model is used to describe the time-varying volatility of $\boldsymbol{Y}_{t}$, and is exploited to identify the structural parameters as in Dungey et al (2010). In particular, following the structure of (3) we write the conditional distribution of the structural innovation $\boldsymbol{u}_{t}$ as

$$
\boldsymbol{B}_{t} \boldsymbol{Y}_{t} \mid \mathcal{I}_{t-1} \sim N\left(0, \boldsymbol{G}_{t}\right)
$$

where $\boldsymbol{G}_{t}=\boldsymbol{g}_{t} \boldsymbol{g}_{t}^{\prime}$ is a $k \times k$ diagonal matrix of the squares of the elements of the matrix $\boldsymbol{g}_{t}$, and $\mathcal{I}_{t-1}$ is the information set available at the end of time period $t-1$.

The conditional covariance matrix of the structural shocks is a $\operatorname{GARCH}(1,1)$ process

$$
\boldsymbol{G}_{t}=\boldsymbol{\Psi} \boldsymbol{\Psi}^{\prime}+\boldsymbol{\lambda} \operatorname{diag}\left(\boldsymbol{u}_{t-1}\right) \operatorname{diag}\left(\boldsymbol{u}_{t-1}\right)^{\prime} \boldsymbol{\lambda}^{\prime}+\boldsymbol{\zeta} \boldsymbol{G}_{t-1} \boldsymbol{\zeta}^{\prime}
$$


where $\boldsymbol{\Psi}, \boldsymbol{\lambda}$ and $\boldsymbol{\zeta}$ are $k \times k$ diagonal matrices. The typical element in $\boldsymbol{G}_{t}$ is,

$$
g_{i, t}^{2}=\Psi_{i}^{2}+\lambda_{i}^{2} u_{i, t-1}^{2}+\zeta_{i}^{2} g_{i, t-1}^{2}
$$

When $\zeta_{i}^{2}+\lambda_{i}^{2}<1$, the unconditional variance is $\boldsymbol{G}=\operatorname{var}\left(\boldsymbol{u}_{t-1}\right)=\left(\boldsymbol{I}_{k}-\boldsymbol{\lambda} \boldsymbol{\lambda}^{\prime}-\boldsymbol{\zeta} \boldsymbol{\zeta}^{\prime}\right)^{-1} \boldsymbol{\Psi} \boldsymbol{\Psi}^{\prime}$, and the GARCH parameters $(\boldsymbol{\Psi}, \boldsymbol{\lambda}, \boldsymbol{\zeta})$ of the structural shocks are assumed to be constant.

\subsection{Variance Decomposition}

The structural GARCH allows for an alternative approach to identifying and interpreting shocks and avoids arbitrary restrictions such as Choleski decomposition or long-run variance assumptions. Once the parameters are identified and estimated, the structural innovations can be isolated, and forecast error variance decompositions can be used to give an interpretation to the sources of the structural innovations. More specifically, we treat the shock which contributes the largest part of a forecast error variance during some base period as emanating from that source. In this way, contagion can be identified not only by the size of changes to contemporaneous linkages but also attributed to a source; as in Dungey et al (2010).

The 1-step ahead conditional forecast error variance for $\boldsymbol{Y}_{t}$ is the fitted value of

$$
\left.\operatorname{var}\left[\boldsymbol{Y}_{t+1} \mid \mathcal{I}_{t}\right)\right]=\boldsymbol{B}_{t+\mathbf{1}}^{-\mathbf{1}} \boldsymbol{G}_{t+\mathbf{1}} \boldsymbol{B}_{t+\mathbf{1}}^{-\mathbf{1}^{\prime}}
$$

using the estimated parameters. Since $\boldsymbol{B}_{t+1}^{-1}$ is a function of time and estimated parameters in $B_{j}$, and $\boldsymbol{G}_{t+1}$ is a function of the information set up to period $t$, this variance is known at the end of period $t$. It gives a variance decomposition that can be assigned to structural shocks, where the percentage of the forecast error variance at time $t$ for $y_{i, t+1}$ that is due to the structural shock $e_{j, t+1}$ is

$$
V D_{i, j,(t+1) \mid t}=\frac{\left(\boldsymbol{B}_{t+1}^{-1} \boldsymbol{g}_{j, t+1} \boldsymbol{g}_{j, t+1}^{\prime} \boldsymbol{B}_{t+1}^{-1^{\prime}}\right)_{i i}}{\left(B_{t+1}^{-1} \boldsymbol{g}_{t+1} \boldsymbol{g}_{t+1}^{\prime} \boldsymbol{B}_{t+1}^{-1^{\prime}}\right)_{i i}} \times 100
$$


and where $\boldsymbol{g}_{j, t+1}$ is the $j$ th column of the matrix $\boldsymbol{g}_{t+1}$. In the results reported below, we link the structural shock $e_{j, t+1}$ to the source variable $y_{i, t+1}$ if $V D_{i, j,(t+1) \mid t}$ is the largest of all $j$.

\section{Identification and Estimation}

Milunovich and Yang (2010) show that, a sufficient condition for the joint identification of the mean and variance parameters in a $k$-dimensional structural VAR-GARCH model is that no structural shocks are degenerate (i.e. entries in $\Psi$ being zero), and that at least $k-1$ structural shocks have ARCH effects. Their result can be used to analyze our smooth transition structural VAR-GARCH model as follows.

Proposition 1 If (i) $\gamma$ is sufficiently large; (ii) no structural shock is degenerate and at least $k-1$ structural shocks have ARCH effects; (iii) $\left(B_{0}, B_{1}, \ldots, B_{N}\right)$ are all invertible and distinct; (iv) $0<c_{1}<c_{2}, \ldots,<c_{N}$, then the structural parameters are locally identifiable at any regular point in the parameter space.

Proof. The reduced form model may be written $\boldsymbol{Y}_{t}=\boldsymbol{B}_{t}^{-1} \boldsymbol{u}_{t}$ and $\boldsymbol{Y}_{t} \mid \mathcal{I}_{t-1} \sim N\left(0, \boldsymbol{H}_{t}\right)$, where $\boldsymbol{H}_{t}=\boldsymbol{B}_{t}^{-1} \boldsymbol{G}_{t} \boldsymbol{B}_{t}^{-1^{\prime}}$. Under (i), in Phase $i(i=0,1,2, \ldots, N)$, the effect on $\boldsymbol{H}_{t}$ of $B_{j}$ for any $j \neq i$ is negligible. Hence, for each $i, B_{i}$ and structural parameters other than $B_{j}$, with $j \neq i$, and $\left(c_{1}, c_{2}, \ldots, c_{N}\right)$ are locally identified in Phase i when (ii) and (iii) hold (Milunovich and Yang 2010). Hence we only need to establish that the phases are identifiable. We note that there are only two possible cases to lose identification of the phases: (a) two or more of $\left(B_{0}, B_{1}, \ldots, B_{N}\right)$ are identical; (b) two or more of $\left(c_{1}, c_{2}, \ldots, c_{N}\right)$ are identical. But these two cases are ruled out by (iii) and (iv). In other words, because the parameters are at a regular point of the parameter space, where the rank of the Jacobian from structural parameters to reduced-form parameters does not change locally, (iii) and (iv) imply that any local changes in $\left(B_{0}, B_{1}, \ldots, B_{N}\right)$ and $\left(c_{1}, c_{2}, \ldots, c_{N}\right)$ have 
non-negligible effects on $\boldsymbol{H}_{t}$. Therefore the proposition holds under the stated conditions.

We estimate the structural model using maximum likelihood, where the log likelihood function is given by

$$
L_{T}(\theta)=-\frac{n k}{2} \ln (2 \pi)-\frac{1}{2} \sum_{t=1}^{T} \ln \left(\left|\boldsymbol{B}_{t}^{-1} \boldsymbol{G}_{t} \boldsymbol{B}_{t}^{-1^{\prime}}\right|\right)+\left(\boldsymbol{Y}_{t}-\boldsymbol{\mu}_{t}\right)^{\prime} \boldsymbol{B}_{t}^{\prime} \boldsymbol{G}_{t}^{-1} \boldsymbol{B}_{t}\left(\boldsymbol{Y}_{t}-\boldsymbol{\mu}_{t}\right)
$$

where $\theta$ denotes the vector of all parameters, $\boldsymbol{\mu}_{t}=E\left(\boldsymbol{Y}_{t} \mid \mathcal{I}_{t-1}\right)=\boldsymbol{\alpha}_{0}+\sum_{j=1}^{p} \boldsymbol{A}_{j} \boldsymbol{Y}_{t-j}$ is the conditional mean, which has been suppressed above for the sake of brevity. In practice, the assumed normality may not be true. Nevertheless, it is well-known that, as long as the conditional mean and the conditional variance are correctly specified and the parameters are identified, the quasi ML estimators based on the normal distribution are consistent (see Gourieroux and Monfort, 1989, p252-253). More specifically, in the context of time series, given the number of regimes, the quasi ML estimators of the structural parameters are consistent and asymptotically normal under a set of general regularity conditions (Bollerslev and Wooldrige, 1992). Among these conditions, the identification of parameters is crucial, which we establish by Proposition 1.

\section{Application to US asset markets: 2001-2010}

Investigations of the financial crisis in 2007-2009 often date the beginning of the crisis from third quarter (August) 2007 in lower frequency analyses, or from August 9, 2007, the date when the ECB began formal intervention in the markets $5^{5}$ Many also consider sensitivity to a start date in September 2008 associated with the collapse of Lehman Brothers, or in 2008 generally as in the overview to the special issue on the crisis in Review of Financial Studies, 24(6). End points for the crisis are various, generally ranging between the end of

\footnotetext{
${ }^{5}$ See, for example, Kalemili-Ozcan, Papaioannou and Perri (2012), Bekaert, Ehrmann, Fratzscher and Mehl (2011), Mishkin (2011).
} 
2008 and mid-2009, pointing to reduced volatility by March 2009, or policy changes by mid-2009. Fry, Hsaio and Tang (2011), Table A4, provide a summary of dating choices for 11 different applications to this period. By applying the method outlined in the previous section, we will endogenously determine the crisis date points, and demonstrate that these are broadly consistent with the start points chosen in the existing literature.

We apply the model to the US financial markets for stocks, Treasury bonds and Real Estate Investment Trusts (REITs). A diversified portfolio might well contain elements of each of these asset classes. While there is some argument about whether REITs behave more like equities or real estate, portfolio managers do recommend them as an attractive component of a portfolio ${ }^{6}$ Given that the US financial crisis had origins in the mortgage markets, and has been associated with a substantial decline in real estate values since 2006, the inclusion of REITs is expected to illuminate some of the changes in the behavior of inter asset linkages during the recent crisis period.

We search for up to three endogenously dated regime changes, and four regimes $B_{j}$, over the sample 7 June 2001 - 16 September 2010 using daily returns from the three asset classes. The values of $c_{j}$ that capture the best break points in the joint structure determine our crisis break points. Estimation is in one step, by quasi maximum likelihood in OX and code is available from the authors on request.

Pre-testing using a general model which allowed the slope parameter of the transition functions, $\gamma_{j}$, to take arbitrary large values, revealed that the estimated values of $\gamma_{j}$ exceeded 10,000. That is, the evidence supports a very rapid transition from crisis and non-crisis phases. For efficiency in the final estimation below, we set the value of $\gamma$ to 100,000 and estimate the remaining coefficients.

The model specification with three potential break points, to incorporate different crisis phases is specified as:

$$
\left[\left(1-S_{3}\right)\left\{\left(1-S_{2}\right)\left[\left(1-S_{1}\right) \boldsymbol{B}_{0}+S_{1} \boldsymbol{B}_{1}\right]+S_{2} \boldsymbol{B}_{2}\right\}+S_{3} \boldsymbol{B}_{3}\right] \boldsymbol{Y}_{t}=\boldsymbol{B}_{t} \boldsymbol{Y}_{t}=\boldsymbol{u}_{t},
$$

\footnotetext{
${ }^{6}$ See, for example,JP Morgan Insights: "The role of REITS in a portfolio", May 2012
} 
where $\boldsymbol{Y}$ contains three asset returns, $y_{i}$ for $i=1,2,3$, and the appropriate value of $B_{j}$ is selected by the value the break point indicators $c_{j}$. When $j=0$, the time fraction transition variable is less than the threshold, so that $x_{t}<c_{1}, j=1$ when $c_{1} \leq x_{t}<c_{2}$, $j=2$ when $c_{2} \leq x_{t}<c_{3}$ and $j=3$ otherwise. Using time as the transition function allows us to proxy for the array of concurrent influences that intensify at the beginning of the crisis and gives a natural interpretation to the thresholds.7

\subsection{Data}

Daily returns for equities, REITs and Treasury bonds are taken for the S\&P500, FTSE NAREITS and Bank of America Merrill Lynch US Treasury index for the period June 7, 2001 to September 16, 2010. The data in levels are shown in Figure 1. The model of the previous section is applied with a $\operatorname{VAR}(4)$ filter.

Results of formal tests for for linear and non-linear dependence at each stage of the estimation are set out in Table 6 (Appendix) and support a well-fitting model overall. While the Hinich (1982) and Jarque-Bera (1980, 1987) tests reject the null of normality, the Lung-Box Q, Tsay (1986) and Hinich (1982) bispectral tests for no autocorrelation and linearity in means are not rejected at the $1 \%$ level for any $e_{i} \cdot 8$

\subsection{Estimated Phase Dates}

We estimate three significant break points, with two standard error intervals equivalent to one week either side of the nominated date (Table 1). The period prior to the first of these breaks is denoted the pre-crisis phase and runs from the beginning of the sample to 1 October 2007. This break is just after the bailout of Northern Rock by British author-

\footnotetext{
${ }^{7}$ Any single financial or economic variable, such as interest rate spreads or measures of market stress (e.g., VIX) captures only one dimension of crisis conditions. Particular policy interventions, announcements or institutional failures are usually discrete and not suitable to be the continuous measure needed for transition functions.

${ }^{8}$ BDS tests (Brock et al. 1996), not reported here, fail to reject pure randomness for all standardized residuals series.
} 
ities (13 September), the lowering of the Federal Funds rate by the US Federal Reserve committee on 18 September and around the time of a large depreciation in the US/Euro exchange rate. UBS announced a large write-down of its fixed interested portfolios on 1 October, Merrill Lynch reported 'startling' losses of $\$ 8.4$ billion on 5 October, and on 10 October, Treasury Secretary Paulson announced the establishment of the HOPE NOW alliance to stave off mortgage foreclosures. This dating is slightly later than much of the existing literature which exogenously dates the start of this phase of the crisis around August 2007.

The model results indicate that the second phase of the crisis began eleven months on in late (20th) August 2008. The bankruptcy of the Lehman Brothers investment bank and subsequent rescue of the American Insurance Group in mid September are the most commonly selected markers for the start of the Global Financial Crisis. However, there are also earlier indications associated with the emerging problems with Fannie Mae and Freddie Mac from July, culminating in those organizations passing into conservatorship on 7 September, and while the crisis at Lehman's hit a low point on 15 September, their losses were announced earlier in the month.

The dating of the third break point, which marks the transition from the crisis to some form of post-crisis period is of considerable interest as there are few obvious event markers. The estimated breakpoint is 18 June 2009, coinciding with the announcement of financial regulatory reform by President Obama. Other signs of recovery around this time, include the Federal Reserve beginning to evaluate applications from banks to redeem U.S. Treasury capital, showing the banks were now able to access long term debt and equity markets without the support of Federal guarantees. Subsequently, the NBER also dated the recession trough as occurring in the June quarter. 


\section{3 $\quad$ Asset Market Linkages}

We assess the evidence for contagion via the changes in linkages between the asset market returns across the different periods. Note that our GARCH framework takes into account the changing nature of the volatility of the markets across time, overcoming the criticisms of spurious contagion results as proposed in Forbes and Rigobon (2002) for example. Since all markets are in crisis at the same time, we do not distinguish contagious effects as external or internal to a market, in Dungey et al (2010). Instead we obtain evidence for the existence and sign of contagion effects between the three markets examined.

The pre-crisis period asset market linkages are all significant, as shown in Table2. The first row of the Table shows that positive shocks to stock returns tend to decrease returns in the Treasury bond index and increase REITs returns. The relationship with REITS may reflect the unusually bouyant conditions in the housing market prior to the crisis (Geanakoplos 2009). Shocks to the REITS market returns are also positively correlated with stock returns pre-crisis, which may reflect the direct effect of housing construction on expected cash flows and on the strong growth of household consumption funded by leveraging housing equity (Mian and Sufi 2010).

In the first crisis phase these linkages change dramatically. Shocks emanating from the T-bond market no longer have a significant effect on other assets; reflecting flight to quality into T-bonds and the potential role of financial frictions, illiqudity, uncertainty over the value of collateral and reluctance to realize losses, all of which dampened the effect of monetary policy (Longstaff 2010; Guidolin and Tam 2010; Hall 2010; and Shleifer and Vishny 2010). In contrast, the impact of equity shocks on REIT returns increases almost ten fold in the first crisis phase. Wald tests for parameter differences between the periods are reported in Table 6 and confirm that this difference is significant.

Contagion effects, in the form of significant changes in the linkages between the different asset classes, are clearly identified in shocks emanating from the equity market to the REITS in both phases of the crisis, and although the estimated coefficient in the 
second phase of the crisis (0.880) is less than that of the first phase (1.048) this difference is not statistically significant and does not represent any change in the extent of contagion experienced from this market in the two phases - particularly in comparison with the significant rise in these linkages from the 0.174 coefficient reported in the pre-crisis phase. If we take a conventional view that mortgage backed securities and the slowdown in the property market were triggers for the crisis events, then the increased sensitivity of the REITS market to equity shocks is consistent with hypersensitivity linkages in the sense of Dungey et al (2010), where hypersensitivity identifies an increased response of a market in crisis to events occuring in other markets. The Wald tests show that although the loadings between other assets change in Table 2 these differences are not statistically significant, and thus there is little evidence for contagion between other assets. Contagion between these markets, in this crisis, is limited to links between the REITS and equity markets.

The results for the post-crisis phase indicate that pre-crisis patterns are not restored. All Wald tests for parameter equality between the pre- and post-crisis phases reject the null hypothesis. We still observe stronger linkages between stock and REIT innovations than during the pre-crisis phase, and insignificant connections between the Treasury bond and stock market innovations, however T-bond and REIT connections are significant at the $10 \%$ level. The coefficient on REIT innovations in the stock equation at 0.173 is about half the pre-crisis estimate of 0.314 , but the coefficient on shocks from stocks to REITs is more than 6 times larger, and significantly different.

\subsection{Dynamics of structural shocks}

Variance decompositions compiled from the estimates in the different phases expose the changes the transmission patterns from stock, bond and REIT market shocks across the period. Table 5 reports the average percentage variance due to different sources at each phase of the crisis. The largest proportion of the variance for each asset return, $y_{i}$, can 
be attributed to a corresponding shock $e_{i}$, so we label them as stock, T-bond and REIT shocks accordingly (see also Dungey et al, 2010, and Diebold and Yilmaz, 2012). In the pre-crisis period, the average percentage of the forecast error variance attributable to the own-market shock is close to $80 \%$. The striking changes between the phases are that during the crisis phases, REITS shocks become more a more important contributor to stock market returns volatility, as they also do for T-bonds in the first phase of the crisis, and correspondingly stock market shocks account for a greater proportion of REITS volatility in the crisis. Strikingly, however, stock market shocks become almost equivalent to own shocks in the REITS market in the post crisis period, accounting for almost half of the observed volatility. The portfolio results are most impressive for the reversal of the importance of REITS and stock shocks in the post crisis period compared with the pre-crisis; consistent with the important changes between these periods noted earlier.

Figure 2 shows more detail on the time profile of the shocks. It graphs the dynamic variance decompositions of the one-step-ahead forecast error variances, treating all estimated parameters as known with certainty, for each asset in panels (a) to (c) and for an equally-weighted portfolio in panel (d). Panels (a) and (d) particularly show that the REIT-sourced shocks became markedly more important several years before the first crisis phase, from early 2004. The growth in REIT shocks coincides with the decision of the U.S. Department of Housing and Urban Development to raise the 'affordable housing' goals of Fannie Mae and Freddie Mac, enabling a large increase in their purchases of securities backed by subprime loans over the next four years. Turbulence from the stock market dominates at the beginning and end of the sample. This pattern is mirrored in panel (c) where the REIT decomposition attributes almost all the forecast error variance to real estate shocks prior to the crisis. However, during and after the crisis equity shocks became increasingly important. Bond shocks dominate bond variance decomposition, panel (b), however a change in the sign of correlation between bonds and stocks in the first phase of the crisis contributes to a much greater proportion of the bond return variance being 
assigned to stock and REIT shocks than during other phases in the sample.

Overall, the application to the US markets during 2001-2010 have endogeneously determined dates for transition into crisis, between phases of the crisis, and finally into a post-crisis period. The dates determined for entry into crisis in 2007 are slightly later than those generally used in the empirical literature - however, as most effects in the early part of the crisis were felt in UK and European markets, this is not inconsistent given our focus on US data. The identification of a change to a second phase of crisis in late August 2008, is earlier than the date of the bankruptcy of Lehman Brothers, but is quite consistent with growing unease in markets over the uncertainty as to whether Lehman Brothers would be rescued. The transition to a post-crisis phase in June 2009 accords with exogeneous dating, but, as with the starting points, has the advantage of being data determined rather than exogenously imposed. This is particularly important as crisis end

points are notoriously difficult to determine. The method also allows contemporaneous detection of changes in the transmission of shocks between assets, and in the example we show evidence of statistically significant contagion effects from equity shocks to REITS returns during the crisis. Ultimately, in the post crisis period, we demonstrate that the transmission linkages between the three assets have not returned to their pre crisis values.

\section{Conclusion}

The Structural GARCH approach with embedded smooth transition functions developed in this paper allows the modelling of the interlinkages between markets subject to changing individual and global volatility while simultaneously endogenously identifying the transition dates between crisis and non-crisis phases. This important innovation means that it is possible to assess the extent of contagion, due to changes in the transmission linkages between non-crisis and crisis periods, while also allowing the model to identify the crisis period from the revealed features of the data. In this way we overcome potentially incor- 
rect assumptions about homogeneity imposed when periods are exogenously demarcated as non-crisis and crisis, and are also able to assess how well institutional and event based dating conventions perform against a data driven alternative.

We illustrate the model for contemporaneous linkages between three key US financial markets; equity, fixed income and real estate, over the period June 7, 2001 to September 16, 2010. We identify four phases during this period - a pre-crisis phase until early October 2007, a first crisis phase until late August 2008, a second crisis phase until June 2009 and a post-crisis phase from June 2009 to the end of the sample. Pre-testing showed that the slopes of transition functions are high implying that switches between phases is rapid. Relative to the event based dates commonly used in the existing literature, our data driven chronology puts the start of the first phase of the crisis slightly later than events (which were primarily European) and the start of the second phase as slightly earlier than the commonly accepted Lehman Brothers' bankruptcy dating convention. The end point of the crisis concurs with the longest of the existing literature in mid-June.

Estimation of the contemporaneous linkages between financial markets prior to the onset of the crisis showed coefficients were significantly different from zero and correlated in conventional ways. However at the onset of the crisis we note that innovations to and from T-bonds to stocks and real estate trusts became insignificant, and in the first stage of the crisis, of unexpected sign. Linkages between REITs and equity innovations became significantly stronger. This pattern persists through the second stage of the crisis and into the recovery period.

The framework and example developed here enrich our ability to empirically understand the dynamics of financial crises, by allowing the data to reveal both the different phases in the evolution of moves from non-crisis to crisis and beyond, and the changing nature of the linkages between assets during those different phases. It reveals that in some instances the event based markers often used to demarcate crisis periods can both underestimate and overestimate the date of transition between phases. 


\section{Appendix: Data sources and tests for model fit}

- Stocks: S\&P500 total returns index, log difference of daily closing values, 6 June 2001 - 16 September 2010; Bloomberg ticker, SPTR.

- Bonds: Bank of America Merrill Lynch Treasury Master, Bond Index, total return, log difference of daily closing values, 6 June 2001 - 16 September 2010; DataStream mnemonic MLGTRSA(RI).

- Real estate: FTSE NAREIT composite total returns index, which includes both price and income returns of all publicly traded real estate investment trusts (equity, mortgage and hybrid), log difference of daily closing values, 6 June 2001 - 16 September 2010; Bloomberg ticker, FNCOTR. 


\section{References}

Bekaert, G., Ehrmann, M., Fratzscher, M. 2012. Global Crises and Equity Market Contagion. NBER Working Paper 17121

Bollerslev, T., Wooldridge, J. M. 1992. Quasi-maximum likelihood estimation and inference in dynamic models with time-varying covariances. Econometric Reviews 11(2): 143-172.

Boyson, N.M., Stahel, C.W., Stulz, R.M. 2010. Hedge fund contagion and liquidity shocks. Journal of Finance LXV(5): 1789-1816.

Brock, W.A., Dechert, A., Lebaron, B., Scheinkman, J.A. 1996. A test for independence based on the correlation dimension. Econometric Reviews 15: 197-235.

Caporale, G.M., Cipollini, A., Spagnolo, N. 2005. Testing for contagion: a conditional correlation approach. Journal of Empirical Finance 12:476-489.

Diebold, F. and Yilmaz, Y. 2012. Better to Given than to Receive: Predictive Directional Measurement of Volatility Spillovers. International Journal of Forecasting 28:57-66.

Dungey, M., Martin, V.L. 2007. Unravelling financial market linkages during crises. Journal of Applied Econometrics 22: 89-119.

Dungey, M., Milunovich, G., Thorp, S. 2010. Unobservable shocks as carriers of contagion. Journal of Banking and Finance 34: 1008-1021

Dungey, M., Fry, R., Gonzalez-Hermosillo, B. and Martin, V. 2011. Transmission of Financial Crises: A Latent Factor Approach. Oxford University Press, New York.

Favero, C., Giavazzi, F. 2002. Is the international propagation of financial shocks nonlinear? Evidence from the ERM. Journal of International Economics 57: 231-46.

Forbes, K., Rigobon, R. 2002. No contagion, only interdependence: Measuring stock market co-movements. Journal of Finance 57: 2223-2261.

Fry, R., Hsiao, C. Y-L., Tang, C. 2011 Actually this time is different. CAMA Working Paper 12/2011, Australian National University, Canberra. http://ssrn. com/abstract= 1861584

Eichengreen B., Rose A.K., Wyplosz, C. 1996. Contagious currency crises. Scandinavian Journal of Economics 98(4): 463484.

Geanakoplos, J. 2009. The leverage cycle. Yale University Cowles Foundation Discussion Paper 1715.

Granger, C. 1993. Strategies for modelling nonlinear time-series relationships. Economic Record 69: 233-38.

Guidolin, M., Tam, Y.M. 2010. A yield spread perspective on the great financial crisis: break-point test evidence. Working Paper 2010-026A, Federal Reserve Bank of St Louis. 
Gourieroux, C., Monfort, A. 1989. Statistics and Econometric Models (vol. 1). Cambridge: Cambridge University Press.

Hall, R. 2010 Why does the economy fall to pieces after a financial crisis? Journal of Economic Perspectives 24: 3-20.

Hinich, M.J. 1982. Testing for Gaussianity and linearity of a stationary time series. Journal of Times Series Analysis 3: 169-176.

Kalemili-Ozcan, S., Papaioannou, E. and Perri, F. 2012. Global Banks and Crisis Transmission. NBER Working Paper 18209, National Bureau of Economic Research, Cambridge MA.

Longstaff, F.A. 2010. The subprime credit crisis and contagion in financial markets. Journal of Financial Economics 97: 436-450.

Jacobs, J.P.A.M., Kuper, G. and Lestano 2005. Identifying Financial Crises in Dungey, M., Tambakis, D. (eds) Identifying Financial Contagion: Progress and Challenges New York: Oxford University Press, pp.86-110.

Jarque, C. M., Bera, A. K. 1980. Efficient tests for normality, homoscedasticity and serial independence of regression residuals. Economics Letters 6: 255-259.

Jarque, C. M., Bera, A. K. 1987. A test for normality of observations and regression residuals. International Statistical Review 55: 163-172.

Mian, A., Sufi, A. 2010. The Great Recession: Lessons from microeconomic data. American Economic Review Papers \& Proceedings, 100: 51-56.

Milunovich, G., Yang, M. 2010. On identifying Structural VAR Models via ARCH Effects. Forthcoming in Journal of Time Series Econometrics.

Mishkin, F. 2011. Over the cliff: From the subprime to the Global Financial Crisis. Journal of Economic Perspectives 25: 49-70.

Pesaran, H., Pick, A. 2007. Econometric issues in the analysis of contagion. Journal of Economic Dynamics and Control 31: 1245-1277.

Shleifer, A., Vishny, R.W. 2010. Asset fire sales and credit easing. American Economic Review 100(2), 46-55.

Silvennoinen A, Teräsvirta T. 2009. Modelling multivariate autoregressive conditional heteroskedasticity with the double smooth transition conditional correlation GARCH model. Journal of Financial Econometrics 7: 373-411.

Tsay, R. S. 1986. Nonlinearity tests for time series. Biometrika 73: 461-466.

van Dijk, D., Teräsvirta, T., Franses, P. 2002. Smooth transition autoregressive models a survey of recent developments. Econometric Reviews 21: 147. 
Figure 1: Trends in asset prices, June 2001 - September 2010

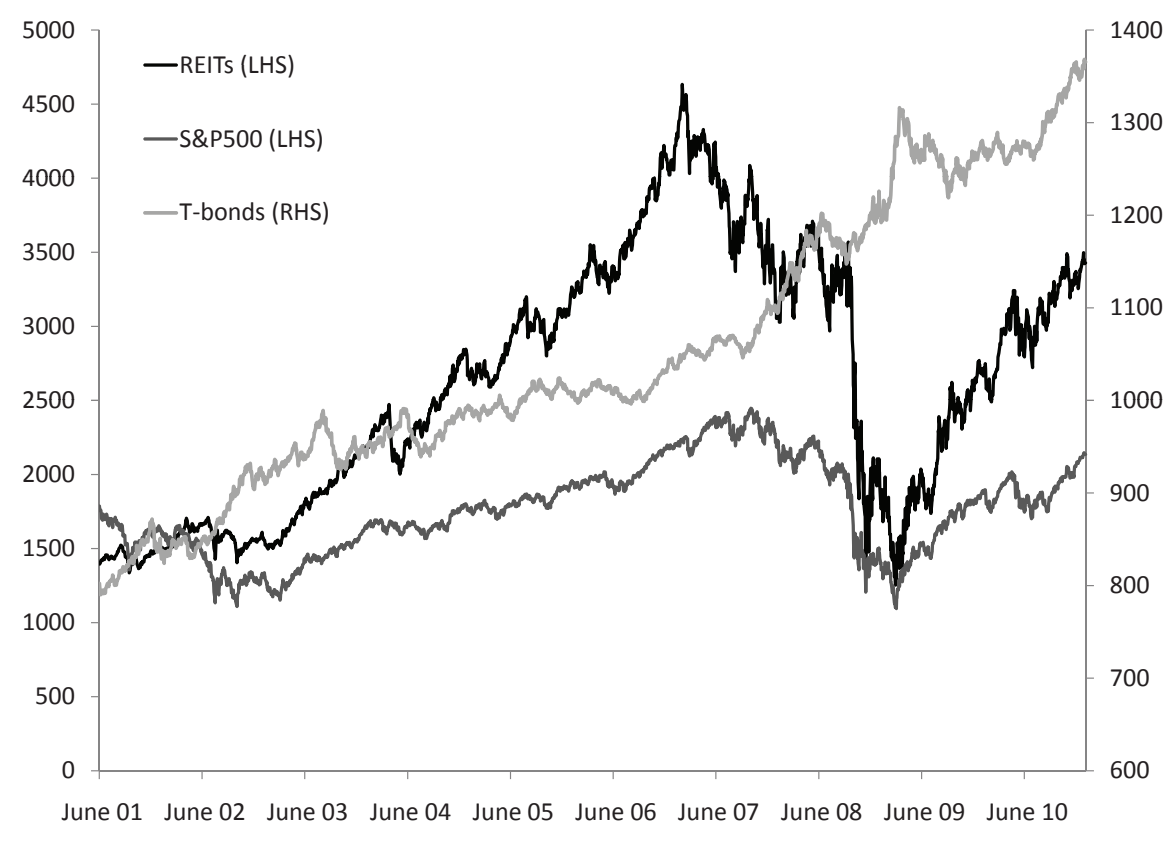

Source: Authors calculations, Bloomberg and DataStream. Figure shows levels of daily closing values for the S\&P500 total returns index, FTSE NAREITs total returns index and the Bank of America Merrill Lynch Treasury Master Bond total returns index. 


\section{Figure 2: Variance decompositions}
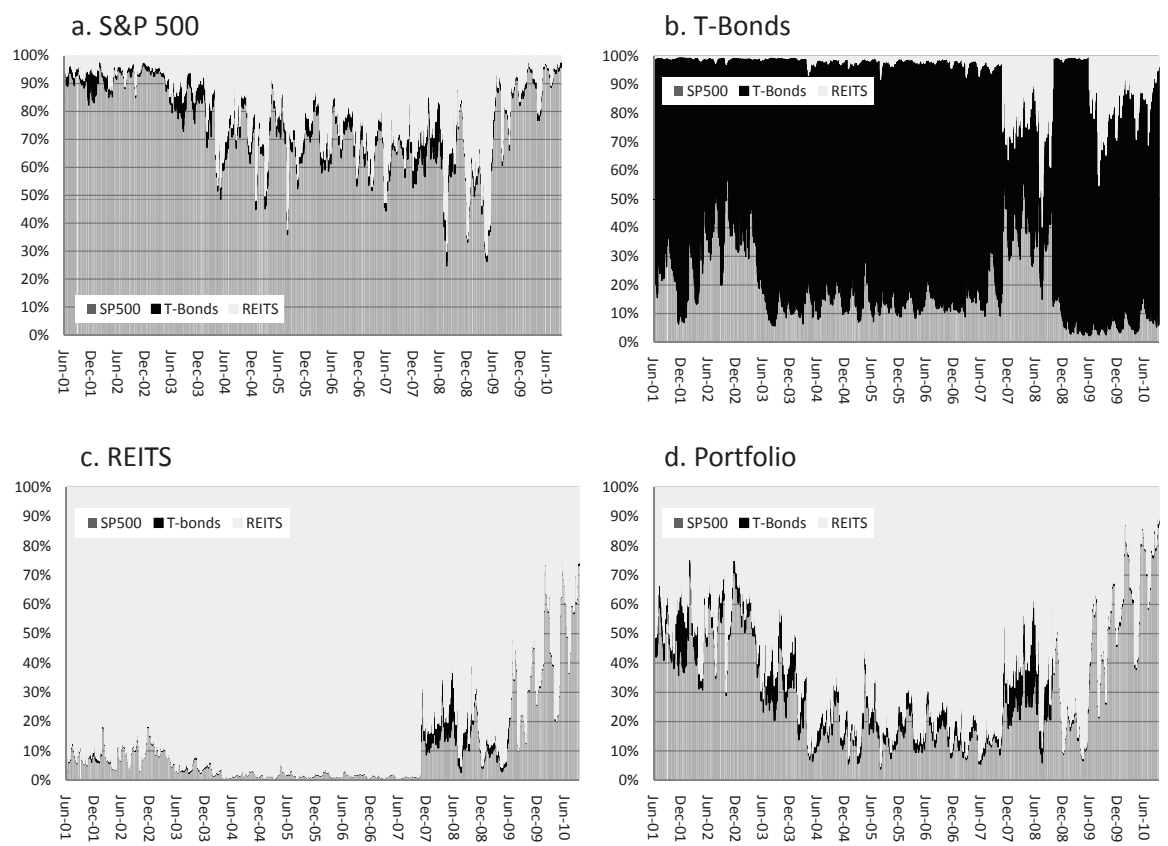

Source: Authors calculations. Figure shows percentage of forecast error variance of $y_{i}$ attributable to structural shock $e_{i} i=1,2,3$ at each observation. 
Table 1: Time threshold parameter estimates

\begin{tabular}{|c|c|c|}
\hline Date & Threshold $\Delta c_{j}$ & \\
\hline 1 October 2007 & $c_{1}$ & $\begin{array}{l}0.679 \\
(0.000)\end{array}$ \\
\hline 20 August 2008 & $\Delta c_{2}$ & $\begin{array}{l}0.097 \\
(0.000)\end{array}$ \\
\hline 18 June 2009 & $\Delta c_{3}$ & $\begin{array}{l}0.089 \\
(0.000)\end{array}$ \\
\hline
\end{tabular}

Note: Parameter estimates for the time thresholds for the crisis phases, $c_{j}$ governed by the smooth transition functions. All estimated threshold parameters have a standard error of 0.001. P-values are in brackets. 
Table 2: Parameter Estimation Results: Pre- to Post-crisis linkages

Pre-crisis phase, 7 June 2001- 1 October 2007

\begin{tabular}{|c|c|c|c|}
\hline & \multicolumn{3}{|c|}{ TO asset $i\left(y_{i}\right)$} \\
\hline & Stocks & Bonds & REITS \\
\hline \multicolumn{4}{|l|}{ FROM asset $j,\left(y_{j}\right)$} \\
\hline \multicolumn{2}{|l|}{ Stocks $b_{i, s}$} & $\begin{array}{c}-0.169 \\
(0.000)\end{array}$ & $\begin{array}{l}0.174 \\
(0.000)\end{array}$ \\
\hline Bonds $b_{i, b}$ & $\begin{array}{l}0.690 \\
(0.005)\end{array}$ & & $\begin{array}{l}-0.289 \\
(0.007)\end{array}$ \\
\hline REITS $b_{i, r}$ & $\begin{array}{l}0.314 \\
(0.000)\end{array}$ & $\begin{array}{l}0.086 \\
(0.000)\end{array}$ & \\
\hline \multicolumn{4}{|c|}{ Crisis phase I, 1 October 2007 - 19 August 2008} \\
\hline \multicolumn{2}{|l|}{ Stocks $b_{i, s}$} & $\begin{array}{l}-0.202 \\
(0.234)\end{array}$ & $\begin{array}{l}1.048 \\
(0.014)\end{array}$ \\
\hline Bonds $b_{i, b}$ & $\begin{array}{l}0.586 \\
(0.629)\end{array}$ & & $\begin{array}{l}1.006 \\
(0.617)\end{array}$ \\
\hline REITS $b_{i, r}$ & $\begin{array}{l}0.385 \\
(0.004)\end{array}$ & $\begin{array}{l}-0.019 \\
(0.842)\end{array}$ & \\
\hline \multicolumn{4}{|c|}{ Crisis phase II, 20 August $2008-17$ June 2009} \\
\hline \multicolumn{2}{|l|}{ Stocks $b_{i, s}$} & $\begin{array}{l}-0.071 \\
(0.643)\end{array}$ & $\begin{array}{l}0.880 \\
(0.008)\end{array}$ \\
\hline Bonds $b_{i, b}$ & $\begin{array}{c}-0.264 \\
(0.818)\end{array}$ & & $\begin{array}{l}-1.149 \\
(0.377)\end{array}$ \\
\hline REITS $b_{i, r}$ & $\begin{array}{l}0.301 \\
(0.000)\end{array}$ & $\begin{array}{l}0.015 \\
(0.794)\end{array}$ & \\
\hline \multicolumn{4}{|c|}{ Post Crisis Phase, 18 June 2009 - 16 September 2010} \\
\hline \multicolumn{2}{|l|}{ Stocks $b_{i, s}$} & $\begin{array}{l}0.038 \\
(0.714)\end{array}$ & $\begin{array}{l}1.259 \\
(0.000)\end{array}$ \\
\hline Bonds $b_{i, b}$ & $\begin{array}{l}-0.585 \\
(0.381)\end{array}$ & & $\begin{array}{l}1.092 \\
(0.097)\end{array}$ \\
\hline REITS $b_{i, r}$ & $\begin{array}{l}0.173 \\
(0.025)\end{array}$ & $\begin{array}{l}-0.093 \\
(0.049)\end{array}$ & \\
\hline
\end{tabular}

Parameter estimates for the model $B_{j} \boldsymbol{Y}_{t}=\boldsymbol{u}_{t}, j=0, \ldots, 3$. P-values are in brackets. 
Table 3: GARCH parameter estimates

\begin{tabular}{llll}
\hline \multicolumn{4}{l}{ Structural Shocks } \\
\hline & Stocks & Bonds & REITS \\
\hline \multirow{3}{*}{ Constant } & 0.024 & 0.003 & 0.031 \\
& $(0.004)$ & $(0.052)$ & $(0.003)$ \\
ARCH & 0.116 & 0.066 & 0.157 \\
& $(0.000)$ & $(0.000)$ & $(0.000)$ \\
GARCH & 0.861 & 0.898 & 0.831 \\
& $(0.000)$ & $(0.000)$ & $(0.000)$ \\
\hline
\end{tabular}

Parameter estimates for the conditional covariance matrix of the structural shocks. Estimation is by QML over daily filtered returns to equity market indices, sampling 7 June 2001 to 16 September 2010. $\mathrm{P}$-values are in brackets. 
Table 4: Wald tests for parameter difference between phases.

\begin{tabular}{|c|c|c|c|}
\hline & \multicolumn{3}{|c|}{$\chi_{1}^{2} \mathrm{p}$-values } \\
\hline \multicolumn{4}{|l|}{ FROM Bonds $b_{12, t}$} \\
\hline & Crisis I & Crisis II & Post-crisis \\
\hline Pre Crisis & 0.932 & 0.419 & 0.074 \\
\hline Crisis I & - & 0.610 & 0.392 \\
\hline Crisis II & - & - & 0.821 \\
\hline \multicolumn{4}{|l|}{ FROM REITS $b_{13, t}$} \\
\hline & Crisis I & Crisis II & Post-crisis \\
\hline Pre Crisis & 0.611 & 0.832 & 0.094 \\
\hline Crisis I & - & 0.555 & 0.163 \\
\hline Crisis II & - & - & 0.175 \\
\hline & & TO Bons & \\
\hline \multicolumn{4}{|l|}{ FROM Stocks $b_{21, t}$} \\
\hline & Crisis I & Crisis II & Post-crisis \\
\hline Pre Crisis & 0.844 & 0.534 & 0.062 \\
\hline Crisis I & - & 0.556 & 0.224 \\
\hline Crisis II & - & - & 0.588 \\
\hline \multicolumn{4}{|l|}{ FROM REITS $b_{23, t}$} \\
\hline & Crisis I & Crisis II & Post-crisis \\
\hline Pre Crisis & 0.270 & 0.244 & 0.000 \\
\hline Crisis I & - & 0.746 & 0.479 \\
\hline Crisis II & - & - & 0.172 \\
\hline
\end{tabular}

\begin{tabular}{lrrr}
\hline \hline & \multicolumn{3}{c}{ TO REITS } \\
FROM Stocks $b_{31, t}$ & Crisis I & Crisis II & Post-crisis \\
\hline & $\mathbf{0 . 0 4 1}$ & $\mathbf{0 . 0 3 3}$ & $\mathbf{0 . 0 0 0}$ \\
Pre Crisis & - & 0.742 & 0.635 \\
Crisis I & - & - & 0.293 \\
Crisis II & & & \\
& & & \\
\hline FROM Binds $b_{32, t}$ & Crisis I & Crisis II & Post-crisis \\
\hline & 0.521 & 0.510 & $\mathbf{0 . 0 3 9}$ \\
Pre Crisis & - & 0.379 & 0.968 \\
Crisis I & - & - & 0.104 \\
Crisis II & & & \\
& & & \\
\hline
\end{tabular}

Table reports p-values for $\chi_{1}^{2}$ statistics for the Wald restriction test of $b_{i j, t}=b_{i j, t+1}$ as $t=0,1,2$. 
Table 5: Variance decompositions: Average percentage by asset and crisis phase.

\begin{tabular}{|c|c|c|c|}
\hline & \multicolumn{2}{|c|}{ Structural shock } & \multirow{2}{*}{$\begin{array}{l}e_{i} \\
\text { REITS }\end{array}$} \\
\hline$y_{i}$ & Stocks & Bonds & \\
\hline \multicolumn{4}{|l|}{ Stocks } \\
\hline Full Sample & 78.1 & 3.6 & 18.3 \\
\hline Pre Crisis & 79.8 & 3.5 & 16.7 \\
\hline Crisis Phase I & 66.1 & 7.4 & 26.4 \\
\hline Crisis Phase II & 61.6 & 2.7 & 35.7 \\
\hline Post Crisis & 89.4 & 1.5 & 9.1 \\
\hline \multicolumn{4}{|l|}{ Bonds } \\
\hline Full Sample & 20.2 & 74.4 & 5.5 \\
\hline Pre Crisis & 21.0 & 77.7 & 1.3 \\
\hline Crisis Phase I & 38.2 & 41.7 & 20.1 \\
\hline Crisis Phase II & 14.1 & 81.4 & 4.5 \\
\hline Post Crisis & 7.3 & 76.5 & 16.2 \\
\hline \multicolumn{4}{|l|}{ REITS } \\
\hline Full Sample & 12.5 & 1.2 & 86.4 \\
\hline Pre Crisis & 4.8 & 0.3 & 94.9 \\
\hline Crisis Phase I & 15.4 & 7.0 & 77.6 \\
\hline Crisis Phase II & 15.3 & 2.8 & 81.9 \\
\hline Post Crisis & 46.8 & 0.4 & 52.8 \\
\hline \multicolumn{4}{|l|}{ Portfolio } \\
\hline Full Sample & 35.2 & 5.3 & 59.5 \\
\hline Pre Crisis & 31.1 & 5.4 & 63.4 \\
\hline Crisis Phase I & 27.9 & 12.9 & 59.3 \\
\hline Crisis Phase II & 28.2 & 2.6 & 69.2 \\
\hline Post Crisis & 65.5 & 0.8 & 33.6 \\
\hline
\end{tabular}

Table reports average percentage of forecast error variance of $y_{i}$ in each crisis phase attributable to $e_{j}$. 


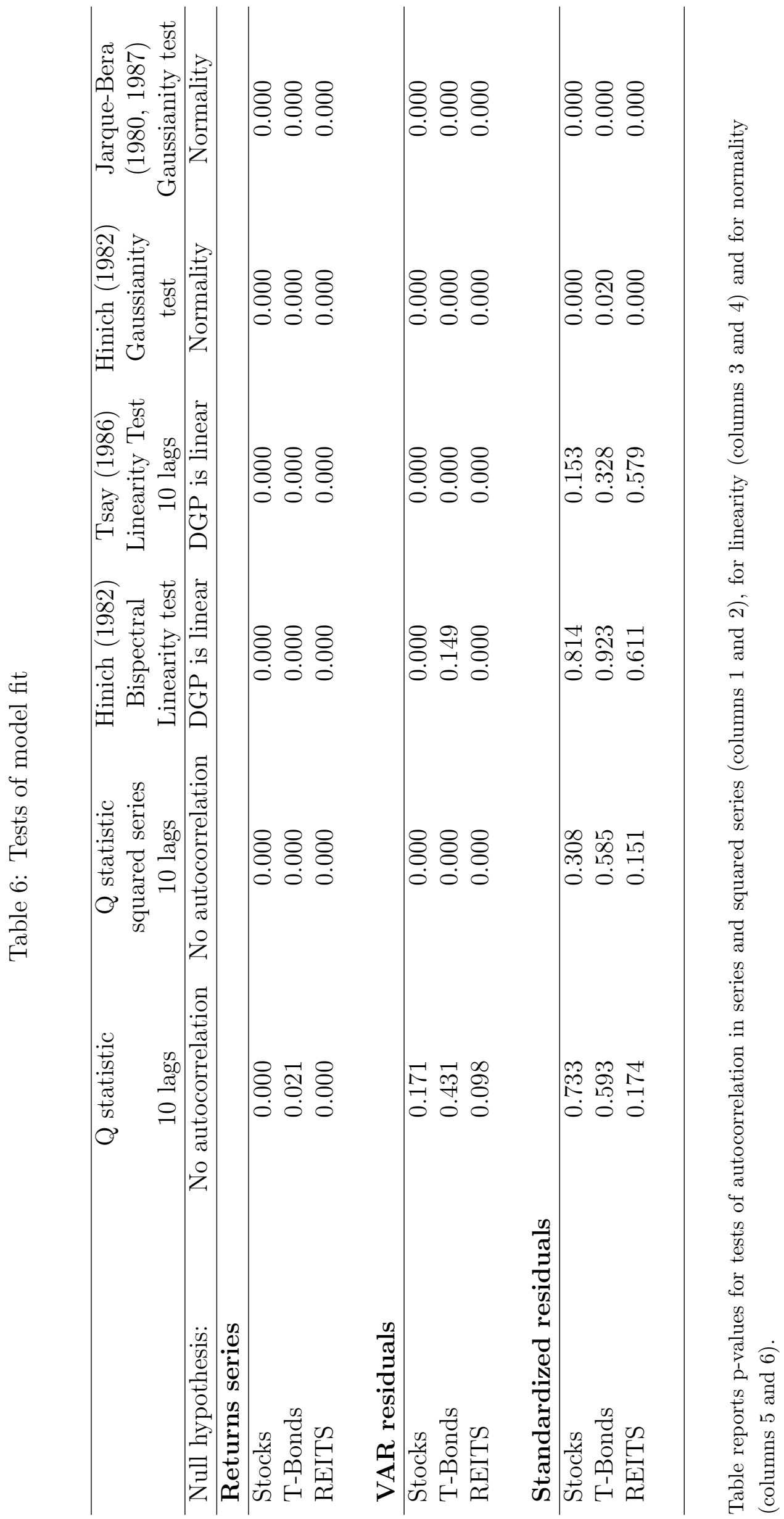




\section{School of Economics and Finance Discussion Papers}

2012-03 Endogenous Crisis Dating and Contagion Using Smooth Transition Structural GARCH, Mardi Dungey, George Milunovich, Susan Thorp and Minxian Yang

2012-02 Testing for Partial Exogeneity with Weak Identification, Firmin Doko Tchatoka

2012-01 On the Correspondence Between Data Revision and Trend-Cycle Decomposition, Mardi Dungey, Jan PAM Jacobs and Jian Tian

2011-06 Systematic and Liquidity Risk in Subprime-Mortgage Backed Securities, Mardi Dungey, Gerald P. Dwyer and Thomas Flavin

2011-05 A SVECM Model of the UK Economy and The Term Premium, Mardi Dungey and M. Tugrul Vehbi

2011-04 Do Contact Matter in the Process of Getting a Job in Cameroon? Firmin Doko Tchatoka and Urbain Thierry Yogo

2011-03 Subset Hypotheses Testing and Instrument Exclusion in the Linear IV Regression, Firmin Doko Tchatoka

2011-02 First home Buyers' Support Schemes in Australia - Results Spreadsheet, Mardi Dungey, Graeme Wells and Sam Thompson

2011-01 First home Buyers' Support Schemes in Australia, Mardi Dungey, Graeme Wells and Sam Thompson

2010-12 Financial Crises in Asia: Concordance by Asset Market or Country?, Mardi Dungey, Jan P.A.M. Jacobs and Lestano

2010-11 Innovation Contracts with Leakage Through Licensing, Shane B. Evans

2010-10 Franchise Contracts with Ex Post Limited Liability, Shane B. Evans

2010-09 Menus of Linear Contracts in Procurement with Type-Dependent Reservation Utility, Shane B. Evans

2010-08 Decomposing the Price Effects on the Cost of Living for Australian Households, Paul Blacklow

2010-07 Modelling the Time Between Trades in the After-Hours Electronic Equity Futures Market, Mardi

Dungey, Nagaratnam Jeyasreedharan and Tuo Li

2010-06 Cojumping: Evidence from the US Treasury Bond and Futures Markets, Mardi Dungey and Lyudmyla Hvozdyk

2010-05 Assessing the Impact of Worker Compensation Premiums on Employment in Tasmania, Paul Blacklow

2010-04 Non-Linear Pricing with Homogeneous Customers and Limited Unbundling, Hugh Sibly

2010-03 Detecting Contagion with Correlation: Volatility and Timing Matter, Mardi Dungey and Abdullah Yalama

2010-02 From Trade-to-Trade in US Treasuries, Mardi Dungey, Olan Henry and Michael McKenzie

2010-01 Economic Assessment of the Gunns Pulp Mill 2004-2008, Graeme Wells

Copies of the above mentioned papers and a list of previous years' papers are available from our home site at http://www.utas.edu.au/economics-finance/research/ 